\title{
Penyelesaian Perhitungan pada Matching Saluran Transmisi $\lambda / 4$ Menggunakan Pemrograman Berbasis Website
}

\author{
Viving Frendiana ${ }^{1}$, Muhammad Teddy Rahmansyah ${ }^{2}$ \\ 1,2 Program Studi Broadband Multimedia, Jurusan Teknik Elektro, Politeknik Negeri Jakarta \\ Jl. Prof. DR. G. A. Siwabessy, Kampus Baru UI, Beji, Depok, Jawa Barat, 16424, Indonesia \\ E-mail: viving.frendiana@elektro.pnj.ac.id
}

\begin{abstract}
Abstrak
Rangkaian matching dengan saluran transmisi $\lambda / 4$, sering disebut juga dengan impedance transformator $\lambda / 4$, adalah saluran transmisi atau pemandu gelombang (waveguide) dengan 1/4 panjang gelombang $(\varphi)$ yg diterminasi dengan impedansi beban. Pada banyak aplikasi diinginkan kondisi tak adanya refleksi pada sambungan saluran transmisi. Oleh sebab itu untuk mengeliminasi refleksi akibat perbedaan impedansi beban dengan impedansi gelombang, dipakai teknik penyamaan/penyesuaian impedansi (impedance matching techniques). Penyepadanan impedansi dilakukan dengan tujuan untuk menyepadankan impedansi beban dengan impedansi karakteristik pada saluran transmisi agar saluran transmisi dapat matching, sehingga proses transmisi pada sejumlah daya tidak terjadi pantulan yang mengakibatkan seluruh daya yang ditransmisikan dapat diserap. Pada penelitian ini, dirancang penyelesaian rangkaian matching saluran transmisi $\lambda / 4$ menggunakan pemrograman berbasis website. Hasil perhitungan simulasi menggunakan aplikasi website didapat nilai impedansi pada saluran transmisi dengan transformator $\lambda / 4$ sesuai dengan perhitungan persamaan matematis. Proses matching pada perhitungan ini mensyaratkan impedansi beban yang riil.
\end{abstract}

Keywords: Impedansi, Pemrograman berbasis web, Rangkaian matching, Sistem transmisi, Transformator $\lambda / 4$

\begin{abstract}
The matching circuit with a $\mathrm{N} 4$ transmission line, often called an impedance transformer $\mathrm{N} 4$, is a transmission line or waveguide with a 1/4 wavelength $(\varphi)$ terminated by the load impedance. In many applications a condition of no reflection is desired at the transmission line connection. Therefore, to eliminate reflections due to differences in load impedance and wave impedance, impedance matching techniques are used. Impedance matching is carried out with the aim of matching the load impedance with the characteristic impedance on the transmission line so that the transmission line can be matched, so that the transmission process for a certain amount of power does not occur reflections which result in all transmitted power being absorbed. In this study, the completion of the $\lambda 4$ transmission line matching circuit was designed using website-based programming. The results of the simulation calculations using the website application obtained the impedance value on the transmission line with the $\mathrm{N} 4$ transformer according to the calculation of the mathematical equation. The matching process in this calculation requires a real load impedance.
\end{abstract}

Keywords: Impedance, Matching circuit, Transmission system, Web-based programming, $\lambda / 4$ transformer

\section{Pendahuluan}

Rangkaian matching bertugas untuk melakukan memadanan dari impedansi beban ke saluran transmisi penyambung. Secara umum, teknik pemadanan bersifat narrow band, berlaku secara sempurna hanya pada suatu titik frekuensi tertentu.

Pada banyak aplikasi diinginkan kondisi tak adanya refleksi pada sambungan saluran transmisi. Oleh sebab SPEKTRAL : Journal Of Communications, Antennas and Propagation itu untuk mengeliminasi refleksi akibat perbedaan impedansi beban dengan impedansi gelombang, dipakai teknik penyamaan/penyesuaian impedansi (impedance matching techniques). Prinsip kerjanya adalah menyisipkan sebuah rangkaian matching di antara beban dan saluran transmisi yang akan dipasangkan [1].

Penyepadanan impedansi dilakukan dengan tujuan untuk menyepadankan impedansi beban dengan impedansi karakteristik pada saluran transmisi agar saluran transmisi Jurusan Teknik Elektro, Politeknik Negeri Jakarta 
dapat matching, sehingga proses transmisi pada sejumlah daya tidak terjadi pantulan yang mengakibatkan seluruh daya yang ditransmisikan dapat diserap.

Tujuan matching impedance:

- Memaksimalkan daya kirim dari sumber ke beban.

- Meminimalisasi rugi - rugi di saluran transmisi.

- Memaksimalkan S/No pada input penerima.

- Meminimalisasi distorsi signal di saluran transmisi.

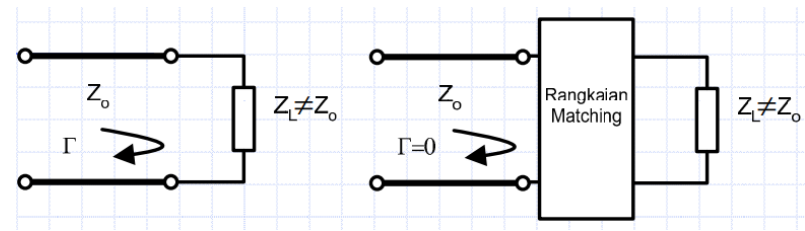

\section{Gambar 1. Prinsip Teknik Rangkaian Matching [1]}

Ada dua jenis transformator impedansi (rangkaian matching) yang bekerja pada interval frekuensi yang sempit (narrow band) dan yang lebar (broad band) [1].

$$
Z_{\text {in }}=Z_{t}\left\{\frac{Z_{L}+j Z_{t} \tan 2 \pi / \lambda(L)}{Z_{t}+j Z_{L} \tan 2 \pi / \lambda(L)}\right\}
$$

Pada transformator $\lambda / 4$, pada bagian $L$ (panjang) diubah menjadi $1 / 4$ lambda. Sehingga menghasilkan persamaan:

$$
Z_{\text {in }}=Z_{t}\left\{\frac{Z_{L}+j Z_{t} \tan 2 \pi / \lambda(\lambda / 4)}{Z_{t}+j Z_{L} \tan 2 \pi / \lambda(\lambda / 4)}\right\}
$$

Dari persamaan di atas dapat disederhanakan lagi, sehingga menghasilkan persamaan:

$$
Z_{\text {in }}=Z_{0}=\frac{Z_{t}{ }^{2}}{Z_{L}}
$$

Persamaan di atas dapat disederhanakan lagi menjadi:

$$
Z_{t}=\sqrt{Z_{0} Z_{L}}
$$

Keterangan:

$\mathrm{Zt}=$ Impedansi transformator $\lambda / 4$

$\mathrm{Z}_{0}=$ Impedansi karakteristik

$Z_{\mathrm{L}}=$ Impedansi beban

Selama ini dalam pengamatan rangkaian matching saluran transmisi $\lambda / 4$ didesain menggunakan dua cara: perhitungan persamaan matematis dan menggunakan bantuan smithchart. Seiring berkembangnya zaman, perlu penyelesaian untuk mendapat ketelitian yang baik dan dalam waktu yang singkat maka perlu bantuan teknologi komputer. Pada penelitian ini, dirancang penyelesaian rangkaian matching saluran transmisi $\lambda / 4$ menggunakan pemrograman berbasis website. Pada pemrograman berbasis website perlu menggabungkan minimal beberapa bahasa pemrograman, yaitu: HTML, CSS, JavaScript dan PHP MySQL.

\section{Metode Penelitian}

Rangkaian matching dengan saluran transmisi $\lambda / 4$, sering disebut juga dengan impedance transformator $\lambda / 4$, adalah saluran transmisi atau pemandu gelombang (waveguide) dengan 1/4 panjang gelombang $(\varphi)$ yg diterminasi dengan impedansi beban. Rangkaian ini menampilkan input dari dua impedansi yang diterminasi. Rangkaian ini mirip dengan konsep stub, tapi rangkaian stub diterminasi dengan rangkaian pendek atau rangkaian terbuka dan panjangnya ditentukan untuk menghasilkan impedansi yang diperlukan. Tetapi rangkaian matching dengan saluran transmisi $\lambda / 4$ bekerja sebaliknya, rangkaian ini menentukan panjang dan terminasinya dirancang untuk menghasilkan impedansi yang dibutuhkan. Hubungan antara karakteristik impedansi $\left(\mathrm{Z}_{0}\right)$, impedansi input $\left(\mathrm{Z}_{\mathrm{in}}\right)$, dan impedansi beban $\left(\mathrm{Z}_{\mathrm{l}}\right)$ adalah $Z_{\text {in }} / Z_{0}=Z_{0} / Z_{L}$.

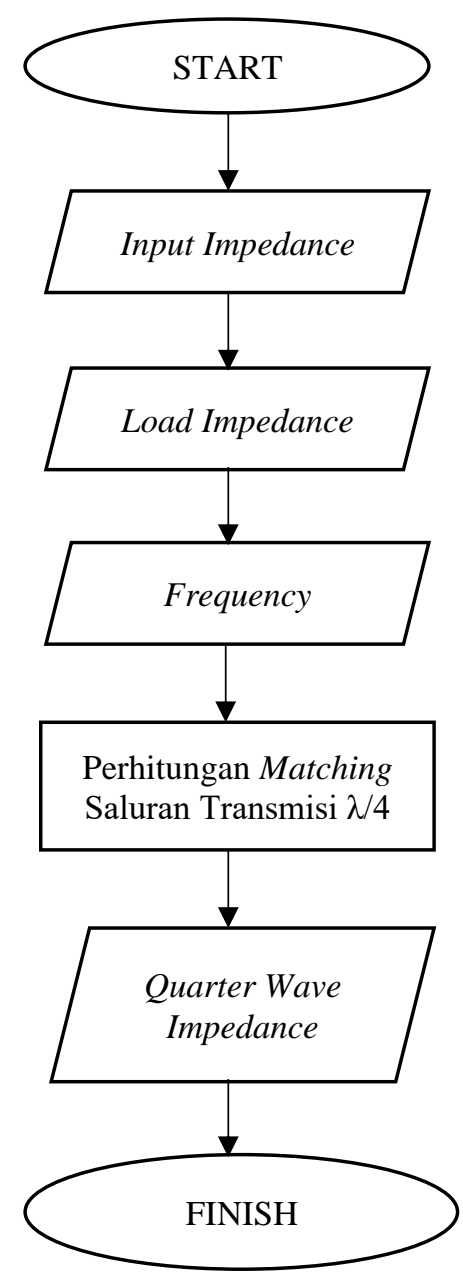

Gambar 2. Flowchart Perhitungan Matching Salauran Transmisi $\lambda / 4$ 
Metode saluran trafo $\lambda / 4$ adalah salah satu metode penyesuaian impedansi dimana sebagai penyesuaian impedansi digunakan saluran dengan panjang $\lambda / 4$ dengan menentukan harga impedansi karakteristik sedemikian rupa sehingga dicapai matching impedansi dari dua media yang dihubungkan. Proses matching ini menyaratkan impedansi beban yang riil

Gambar 2 menunjukkan flowchart perhitungan matching saluran transmisi $\lambda / 4$. Tahap pertama adalah menginput nilai dari impedansi input, impedansi beban dan frekuensi yang digunakan. Selanjutnya dilakukan proses perhitungan matching saluran transmisi $\lambda / 4$ menggunakan rumus $Z_{01}=\frac{Z^{2}{ }_{02}}{R_{R}}$. Dari hasil perhitungan tersebut akan didapat nilai impedansi matching seperempat gelombang. Perhitungan diatas adalah untuk impedansi beban yang riil. Apabila impedansi beban tidak riil maka diperlukan proses untuk menjadikan riil terlebih dahulu dengan menambahkan sebuah saluran transmisi. Hasil transformasi ini menjadi riil, jika diputar sampai impedansi beban itu ke posisi tegangan maksimum (pada sumbu riil positif) atau ke posisi tegangan minimum (pada sumbu riil negatif) sehingga hanya satu panjang saluran transmisi tertentu saja yang harus dipasangkan Atau dengan cara menggunakan komponen kapasitor/induktor yang bertugas untuk mengkompensasikan komponen reaktif di beban, sehingga transformator $\lambda / 4$ didapatkan beban riil.

Pada Gambar 3 merupakan alur flowchart dari pembuatan sistem penyelesaian perhitungan matching salurang transmisi $\lambda / 4$. Tahap pembuatan diawali dengan merancang dasar web dengan HTML (Hypertext Markup Languange). HTML merupakan bahasa markup standar untuk membuat dan menyusun halaman dan aplikasi web. Langkah berikutnya merancang design halaman home dan halaman perhitungan menggunakan CSS (Cascading Style Sheets), langkah ini dibutuhkan untuk mengatur seluruh tampilan website sehingga terlihat lebih menarik. Kemudian langkah yang paling penting adalah merancang perhitungan impedansi $\lambda / 4$ menggunakan javascript dan php sehingga website lebih dinamis dan interaktif. Tahap terakhir adalah intergrasi semua bahasa pemrograman dan memastikan website berjalan sesuai dengan fungsionalitasnya.

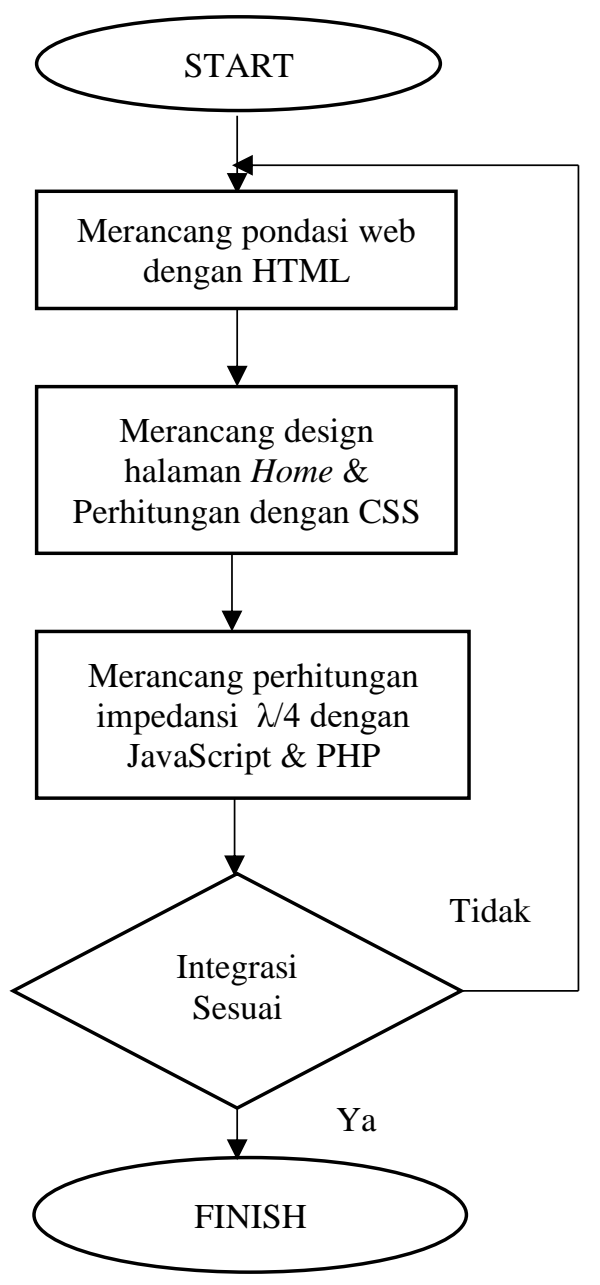

Gambar 3. Flowchart Pembuatan Sistem

\section{Hasil dan Pembahasan}

Program ini membutuhkan XAMPP untuk dijalankan. Folder program ini harus berada di directory khusus yang ada di dalam XAMPP. C:/xampp/htdocs/(folder program)

Cara menjalankan program:

1. Install XAMPP Control Panel

2. Aktifkan/start server apache yang ada di xamppcontrol-panel

3. Masuk ke web browser dan ketik http://localhost/dashboard/

4. Ganti url /dashboard/ menjadi folder program http://localhost/(folder program)/

5. Untuk kasus ini: http://localhost/sistemtransmisiphp/ 


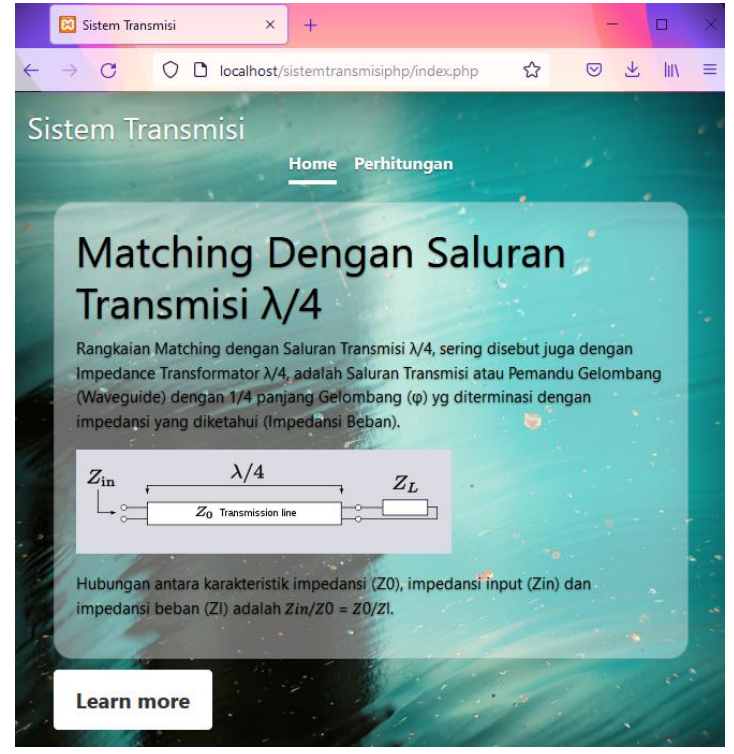

Gambar 4. Tampilan Halaman Home

Gambar 4 menunjukkan tampilan halaman home yang berisi informasi perihal teori rangkaian matching dengan saluran transmisi $\lambda / 4$. Apabila button Learn more diklik maka halaman akan dialihkan ke website wikipedia yang membahas tentang saluran transmisi dengan transformator $\lambda / 4$.

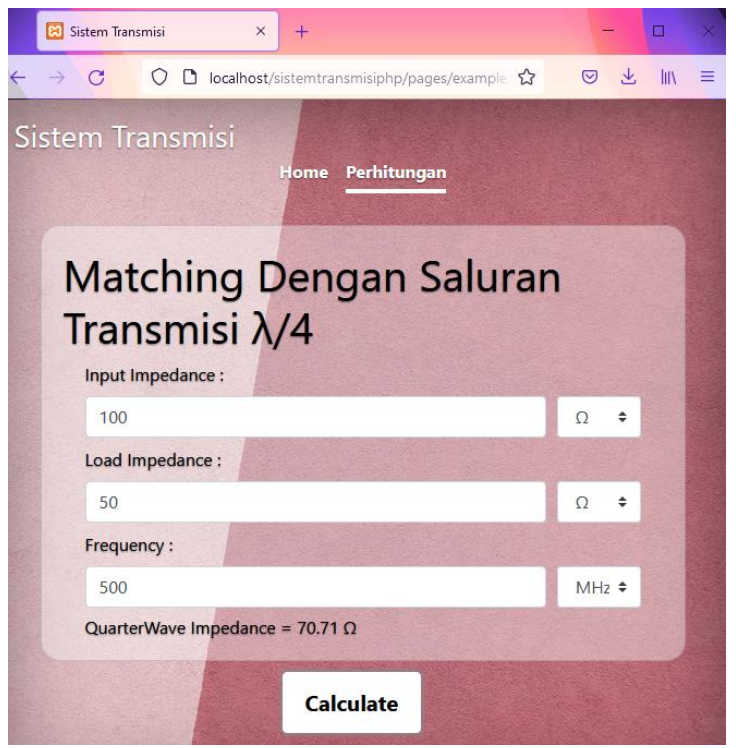

Gambar 5. Tampilan Halaman Perhitungan

Pada Gambar 5 menampilkan hasil perhitungan dari sebuah rangkaian matching dengan saluran transmisi $\lambda / 4$ mempunyai impedansi beban yang riil. Impedansi adalah gabungan nilai hambatan yang dihasilkan oleh beban berupa resistor yang dihubungkan dengan kapasitor atau induktor. Input Impedance adalah impedansi input atau impedansi masukan dengan satuan Ohm. Load Impedance adalah impedansi beban dengan satuan Ohm.
Sedangkan Frequency adalah nilai frekuensi yang dipakai dengan satuan Hertz. Semua parameter yang diinputkan pada masing-masing textfield harus berupa angka, apabila yang diinputkan berupa huruf, karakter atau simbol maka akan muncul pesan "inputan harus berupa angka".

Impedansi input adalah sebesar $100 \Omega$ dan impedansi beban sebesar $50 \Omega$. Sedangkan frekuensi disetting pada nilai $500 \mathrm{MHz}$.

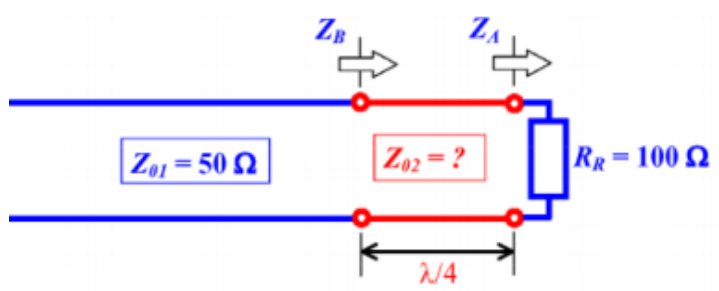

Gambar 6. Rangkaian Matching dengan Transformator $\lambda / 4$ [1]

$$
\begin{aligned}
& Z_{B}=\frac{Z^{2}{ }_{02}}{R_{R}}=Z_{01} \\
& Z_{02}=\sqrt{Z_{01} \cdot R_{R}} \\
& Z_{02}=\sqrt{50.100}=70,71 \Omega
\end{aligned}
$$

Sebuah rangkaian matching dengan saluran transmisi $\lambda / 4$ mempunyai impedansi beban yang riil ditunjukkan pada Gambar 6. Diketahui nilai input impedansi $50 \Omega$ dan impedansi beban $100 \Omega$. Secara perhitungan didapat nilai impedansi pada saluran transmisi sebesar $70,71 \Omega$.

Dari hasil perhitungan menggunakan rumus dan secara simulasi menggunakan aplikasi website didapatkan hasil yang sama yaitu nilai impedansi pada saluran transmisi dengan transformator $\lambda / 4$ adalah $70,71 \Omega$.

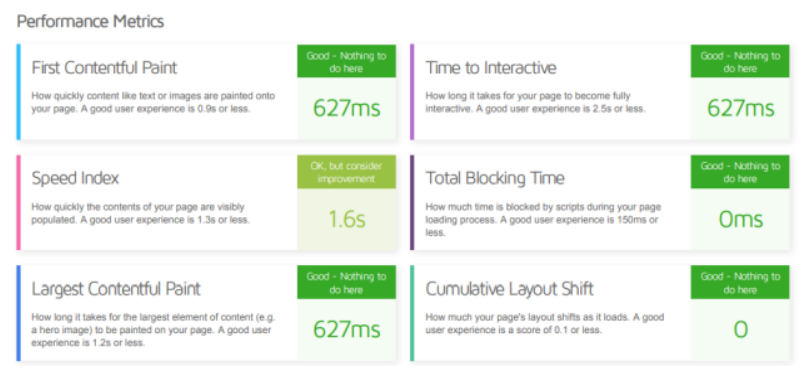

\section{Gambar 7. Performance Metrics}

Performa kinerja website dianalisa menggunakan GTmetrix untuk menganalisis dan mengoptimalkan situs web. Dari tabel performance metrics dapat diketahui nilai First Contentful Paint termasuk kategori bagus yaitu sebesar 627 ms. First Contentful Paint adalah parameter seberapa cepat konten seperti teks atau gambar di-load pada halaman website. Sedangkan nilai speed index tergolong baik dengan nilai berkisar 1.6 detik, namun 
perlu ditingkatkan karena nilai good user experience yang baik untuk speed index adalah 1.3 detik atau kurang dari itu. Parameter lain seperti Largest Contentful Paint, Time to Interactive, Total Blocking Time dan Cumulative Layout Shift termasuk dalam kriteria bagus

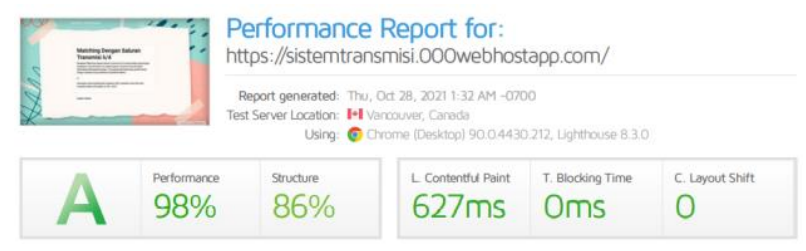

\section{Gambar 8. Performance Report}

Website yang berhasil dibuat dihosting dengan nama domain https://sistemtransmisi.000webhostapp.com/. Kinerja website ditest dengan memilih Vancouver, Canada sebagai lokasi pengecekan tes kecepatan. Berdasarkan performance report diperoleh nilai performa $98 \%$ dan struktur $86 \%$ artinya performa dan kecepatan website sangat baik.

\section{Kesimpulan}

Rangkaian matching dengan saluran transmisi $\lambda / 4$ bekerja dengan menentukan panjang dan terminasinya, dirancang untuk menghasilkan impedansi yang dibutuhkan. Hasil perhitungan simulasi menggunakan aplikasi website didapat nilai impedansi pada saluran transmisi dengan transformator $\lambda / 4$ sesuai dengan perhitungan persamaan matematis. Proses matching pada perhitungan ini mensyaratkan impedansi beban yang riil.

\section{Daftar Acuan}

[1] M. Alaydrus, Saluran Transmisi Telekomunikasi, Graha Ilmu, Yogyakarta, 2009, p.107.

[2] D.P. Wati, I. Santoso, A.A. Zahra, Simulasi Smith Chart Untuk Penyesuai Impedansi Tipe Trafo $1 / 4 \lambda$ dan Tipe Single Stub. Universitas Diponegoro, Semarang (2015).

[3] B. S. Subagio, Saluran Transmisi Frekuensi 850-950 $\mathrm{MHz}$. Menggunakan Teknologi Microstrip. Politeknik Negeri Semarang, Semarang (2014).

[4] Roger L. Freeman, "Fundamental of Telecommunication", John Wiley \& Sons, 1999.

[5] Principle and Application of Optical Communication, Ming Max, Liu Kang Mc-Graw Hill Companies, inc 1996.

[6] M. Alaydrus, Prinsip dan Aplikasi Antena, Graha Ilmu, Jakarta, 2011.

[7] B. S. Nugroho, F. Y. Zulkifli, and E. T. Rahardjo, Lossy-Transmission-Line Analysis of Frequency Reconfigurable Rectangular-Ring Microstrip Antenna. International Journal of Microwave Science and Technology (2014).

[8] A. Dingli and S. Cassar, An Intelligent Framework for Website Usability. Advances in HumanComputer Interaction (2014).

[9] D. Sulasih, A. Tarmuji, Analisis Website Universitas Ahmad Dahlan dengan Metode Usability Testing. Jurnal Sarjana Teknik Informatika (2015).

[10] Nurhayati. Analisa Website Puslit Indonesia Dengan Menggunakan Webqual Untuk Pengukuran Kualitas Website. Jurnal Sistem Informasi dan Telematika (2013). 